Hetherington, A. W., and Ranson, S. W. (1942). Spontaneous activity and food intake of rats with hypothalamic lesions. American Fournal of Physiology, 136, 609.

Illig, R., Ischymi, A., and Vischer, D. (1974). The Various Faces of Diabetes in fuveniles. Proceedings of the 2nd International Beilinson Symposium, October 1972. Ed. by Z. Laron and M. Karp. Karger, Basel.

Kilo, C., Vogler, N., and Williamson, J. R. (1972). Muscle capillary basement membrane changes related to aging and to diabetes mellitus. Diabetes, 21, 881.

Kornerup, T. (1955). Studies in diabetic retinopathy. An investigation of 1,000 cases of diabetes. Acta Medica Scandinavica, 153, 81.

Larsson, S. (1954). On the hypothalamic organisation of the nervous mechanism regulating food intake. Acta Physiologica Scandinavica, 32, Suppl. 115.

Okun, E., Johnston, G. P., and Boniuk, I. (1971). Management of Diabetic Retinopathy. Mosby, St. Louis.

Osterby, R. (1974). Electron microscopy of vascular changes in juvenile diabetes. In The Various Faces of Diabetes in Fuveniles. Proceedings of the 2nd International Beilinson Symposium, October 1972. Ed. by Z. Laron and M. Karp. Karger, Basel.

Savir, H. (1974). Vascular changes in the eyes of young diabetics. In The Various Faces of Diabetes in Fuveniles. Proceedings of the 2nd International Beilinson Symposium, October $1972 . \quad \mathrm{Ed}$. by Z. Laron and $M$. Karp. Karger, Basle.

A. SAVIR, Z. Dickerman, M. KARP, and Z. LARON* From the Department of Ophthalmology and The Institute of Paediatric and Adolescent Endocrinology, Beilinson Medical Centre, Petah Tiqva, Sackler School of Medicine, Tel Aviv University, Israel.

*Correspondence to Professor Z. Laron, Institute of Paediatric and Adolescent Endocrinology, Beilinson Hospital, Petah Tiqva, Israel.

\title{
'Moyamoya' associated with peripheral vascular occlusive disease
}

Moyamoya is a condition characterized by multiple occlusions of the cerebral circulation with an unusual net-like system of collaterals. The majority of patients previously reported have been Japanese.

This report is of an Australian boy, and is unique in describing the previously unreported occurrence of moyamoya with peripheral vascular occlusions.

\section{Case report}

The patient is a boy of Anglo-Saxon origin who presented at the age of 13 years with an acute hemiplegia. At the age of 6 months, he developed chilblains on his hands. These have recurred with increasing severity in cold weather, resulting in small areas of gangrene on his hands and feet and loss of tissue from the tips of his ears (Fig. 1). Because of the severity of the chilblains, he was first seen at the Royal Children's Hospital, aged 2 years. At regular examinations throughout his life he was noted to have good peripheral pulses and the only

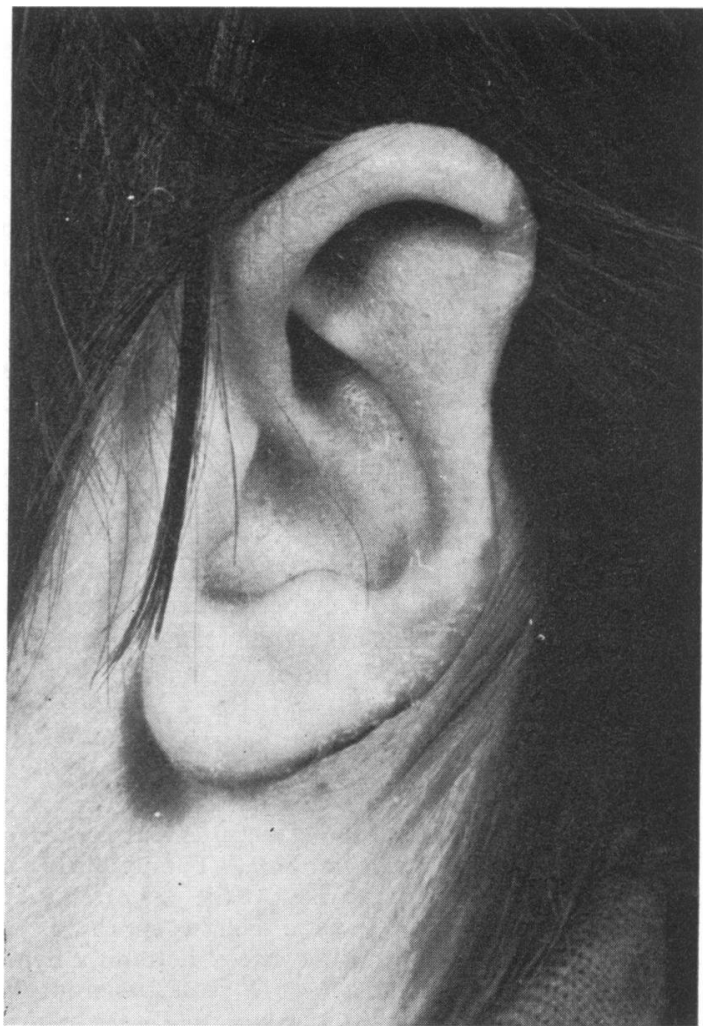

Fig. 1.-Loss of tissue from ear.

satisfactory management was avoidance of cold. At 6 years of age he was seen because of unsteadiness of gait and subsequent chorea, followed by slurred speech and emotional lability. His chorea and slurred speech persisted for 6 months but emotional lability has continued to the present time.

He was first seen by the author at 13 years of age when he presented with an acute left hemiplegia. On examination he was disorientated with a profound left hemiplegia. Blood pressure was $130 / 80 \mathrm{mmHg}$ and all peripheral pulses were easily palpable. He was discharged after 3 weeks, his disabilities being a mild left hemiparesis, squeaky voice, and hyperactivity. When reviewed 12 months later he showed minimal weakness of his left arm and leg, further scarring, and tissue loss from digits and ears, and for the first time a very small area of gangrene at the tip of his nose.

\section{Investigations.}

Angiography. 2 days after onset of hemiparesis carotid angiography revealed narrowing of the supraclinoid portions of both internal carotid arteries, occlusion of the anterior and middle cerebral vessels just distal to their origins from the internal carotid arteries, and a vast network of fine collateral vessels in the region 
of the basal ganglia. The occluded vessels filled through the collateral network and also by leptomeningeal anastomoses.

Arteriography of the left forearm and hand showed occlusion of the ulnar artery just above the wrist and very slow circulation in the hand, fingers, and thumb. The digital vessels to the thumb and index finger were occluded and the only supply to the middle, ring, and little fingers arose from a very fine anterior interosseous vessel (Fig. 2). Arteriography of the left leg and foot was normal.

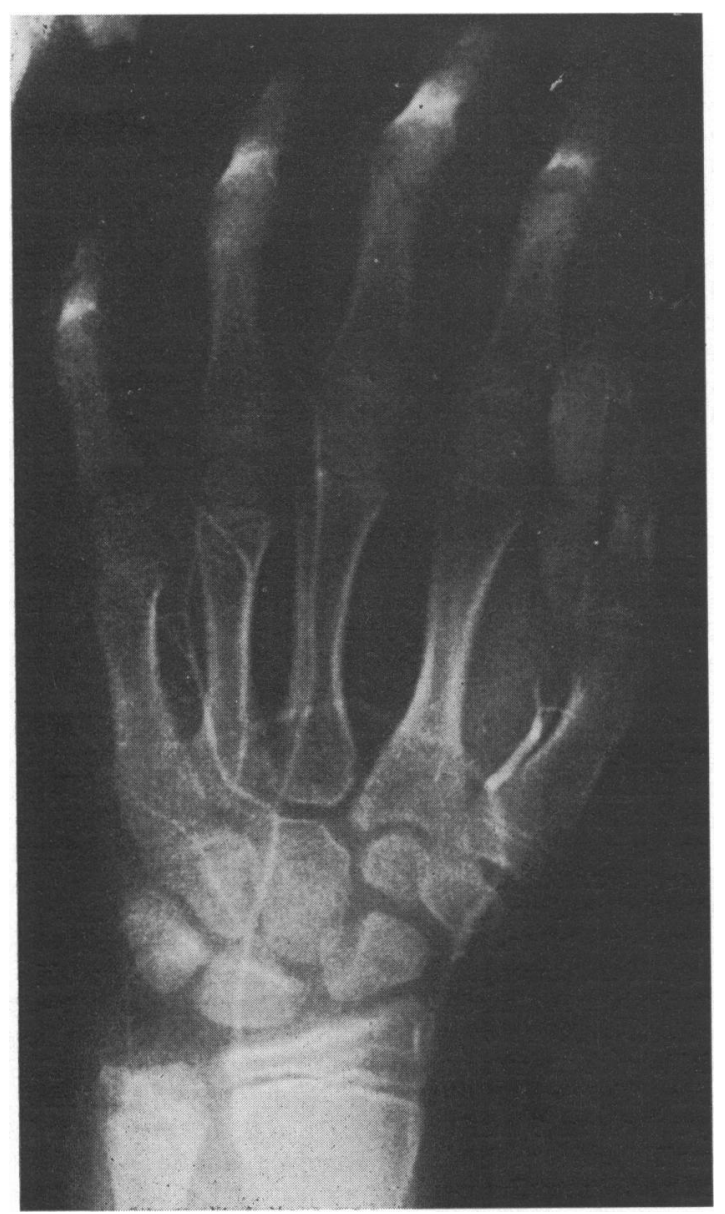

FIG. 2.-Arteriogram of the left hand showing occlusion of the ulna artery, the anterior carpal arch, and several of the metacarpal vessels. The left little and ring fingers are supplied by way of the anterior interosseous artery.

Histology. Temporal artery biopsy showed slight intimal thickening in one area. Muscle biopsy (quadriceps) showed a small amount of fatty infiltration but otherwise no histological abnormality was seen in either specimen.
Lipoprotein electrophoresis showed an increased pre- $\beta$ band consistent with increased endogenous triglyceride. Serum endogenous triglyceride rose normally after a carbohydrate load. Fasting triglyceride was $145 \mathrm{mg} / 100 \mathrm{ml}$ and cholesterol was $96 \mathrm{mg} / 100 \mathrm{ml}$. Glucose tolerance test showed a flat curve with a fasting level of $90 \mathrm{mg} / 100 \mathrm{ml}, 97 \mathrm{mg}$ at 1 hour and $108 \mathrm{mg}$ at 2 hours.

Full blood examination, erythrocyte sedimentation rate, serum proteins, urine for lead, and porphyrins were within normal limits. Autoimmune studies, which included screening against lymphocyte nuclei, granulocyte nuclei, thyroid cytoplasm, gastric parietal cells, smooth muscle, and cell mitochondria, were also negative as were repeated tests for LE cells.

\section{Discussion}

Moyamoya is essentially an arteriographic diagnosis. There is narrowing of the distal internal carotid artery and the proximal parts of its major branches, together with multiple occlusions. The changes are usually bilateral but one side is often more affected than the other; the vertebrobasilar system may also be affected. Characteristically there occurs an extensive net-like system of collateral vessels.

The radiological abnormalities have been well described by Taveras (1969). Suzuki and Takaku (1969) described a dynamic progression of lesions, starting with spasm around the carotid bifurcation. Their findings have not been supported by other authors who have followed patients with repeat angiography.

Four necropsy cases have been described (Isler, 1971; Halonen et al., 1973), the common histological features being thickening of the intima without associated changes in the media or adventitia, and no inflammatory changes. One, a 12-year-old girl, showed associated atherosclerotic lesions of the carotid arteries and 2 had associated tuberculosis. One case showed changes in a renal and coronary artery.

A variety of theories have been advanced as to the cause of this condition, none of which are entirely satisfactory. A primary malformation of the blood vessels has been suggested by Galligioni et al. (1971). They support this by claiming an association with other congenital abnormalities such as aneurysms, by the uniform narrowing of the calibre of the internal carotid artery, by the pseudoangiomatous pattern of the collaterals, and the lack of progression of the disease. This theory would be supported by the evidence of diffuse vascular disease dating from infancy in our patient. The widespread nature of the disease in our patient would imply a primary defect of vessel wall rather than a local vascular 
abnormality with perhaps secondary changes. The late onset of many of the reported cases could be ascribed to superimposed stresses, such as ageing producing a critical diminution of functional reserves in the cerebral circulation. It is not clear whether the network of collaterals is primarily a part of the initial malformation or a response to the progressive narrowing of the carotid system. The significance of the intimal thickening, the only consistent histological feature, is also not clear.

Other theories have even less to support them. These include a response to trauma or inflammation, the possibility of an autoimmune process, or a relation to atherosclerosis or hypertension.

\section{Summary}

A case is described of an Australian boy with moyamoya associated with peripheral vascular involvement manifest as severe chilblains since infancy. He developed an acute hemiplegia at age 13. Despite intensive investigation, no underlying cause was found for this condition. The early onset and diffuse occurrence of vascular disease gives some support to the theory that there is a primary abnormality of the blood vessels.

The help of F. Jensen, Director of Radiology, Mr. P. G. Jones, and Drs. I. J. Hopkins, T. B. Maddison, and H. N. B. Wettenhall, members of staff of the Royal Children's Hospital, is gratefully acknowledged.

\section{REFERENCES}

Galligioni, F., Andrioli, G. C., Marin, G., Briani, S., and Iraci, G. (1971). Hypoplasia of the internal carotid artery associated with cerebral pseudoangiomatosis-report of four cases. American fournal of Roentgenology, Radium Therapy and Nuclear Medicine, 112, 251.

Halonen, H., Halonen, V., Donner, M., Iivanainen, M., Vuolio, M., and Makinen, J. (1973). Occlusive disease of intracranial main arteries with collateral networks in children. Neuropaediatric, 4, 187.

Isler, W. (1971). Multiple occlusions with unusual net-like collaterals ('Moyamoya' disease). In Acute Hemiplegias and Hemisyndromes in Childhood, p. 50. Clinics in Developmental Medicine, 41/42. Heinemann, London.

Suzuki, J., and Takaku, A. (1969). Cerebrovascular 'Moyamoya' disease. Archives of Neurology, 20, 288.

Taveras, J. M. (1969). Multiple progressive intracranial arterial occlusions. A syndrome of children and young adults. Americal fournal of Roentgenology, Radium Therapy and Nuclear Medicine, 106, 235.

H. JAMES GOLDBERG

Royal Children's Hospital, Parkville, Victoria, 3052, Australia.

\section{Fatal septicaemia due to Moraxella non liquefaciens}

The organism Mima polymorpha or Moraxella ron liquefaciens is known to cause serious infections.
The members of the genus Moraxella are similar to Neisseria in morphology, biochemical reactions, growth characteristics, nutrient requirements, antibiotic sensitivity, and habitat, and there has been controversy regarding its taxonomy and bacterial sensitivity. We have encountered a case of Moraxella non liquefaciens septicaemia with bilateral adrenal haemorrhages clinically resembling meningococcaemia.

\section{Case report}

A 5-month-old boy, born after term normal delivery with birthweight $3355 \mathrm{~g}$ to healthy parents, was admitted to hospital with a history that he was unwell with coryza for one week. He had been refusing feeds, and became drowsy, lethargic, and febrile one day before admission.

At the age of 9 weeks he had been hospitalized with an attack of fulminant bronchopneumonia and was critically ill; he had been treated with ampicillin and recovered completely in 10 days. Subsequently he had two episodes of upper respiratory tract infection and an attack of croupy cough. These illnesses were treated by the family doctor and required no hospitalization.

On examination he was found to be endomorphic in build, weight $13.5 \mathrm{~kg}$, temperature $39.5^{\circ} \mathrm{C}$, pulse rate $168 / \mathrm{min}$, respiratory rate $35 / \mathrm{min}$. He was pale, peripherally cyanosed, drowsy, and dehydrated, irritable on waking. and showed no interest in feeds. Mucoid secretions were seen with crusting at the nostrils, there was no skin rash and no lymphadenopathy. The liver and spleen were not palpable. Cardiovascular and respiratory systems were normal. No abnormal neurological signs were elicited. $\mathrm{Hb} 10.6 \mathrm{~g} / 100 \mathrm{ml}$; packed cell volume $34 \%$; mean corpuscular haemoglobin concentration $35 \%$; platelets $200,000 / \mathrm{mm}^{3}$; RBC 4 million $/ \mathrm{mm}^{3}$; WBC $3600 / \mathrm{mm}^{3}$; polymorphs $9 \%$; lymphocytes $89 \%$; monocytes $2 \%$. Peripheral smear showed normochromia with mild variation in size. Plasma sodium $139 \mathrm{mEq} / \mathrm{l}$, , chloride $104 \mathrm{mEq} / 1$., potassium $4.9 \mathrm{mEq} / 1$, urea $59 \mathrm{mg} / 100 \mathrm{ml}$, creatinine 0.8 $\mathrm{mg} / 100 \mathrm{ml}$; blood $p \mathrm{H} \mathrm{7} \cdot 13 ; \mathrm{Po}_{2} 27 \cdot 6, \mathrm{PcO}_{2} 51 \cdot 8 \mathrm{~mm} \mathrm{Hg}$; buffer base 33 , standard bicarbonate 16 , base deficit -13 $\mathrm{mEq} / \mathrm{l}$. Chest $x$-ray showed overdistension of the lung fields with no areas of consolidation or collapse. CSF was slightly blood-stained with $1560 \mathrm{RBC} / \mathrm{mm}^{3}$, lymphocytes $3 / \mathrm{mm}^{3}$; protein $36 \mathrm{mg} / 100 \mathrm{ml}$; sugar 88 $\mathrm{mg} / 100 \mathrm{ml}$; culture was negative. Urine and blood cultures grew Gram-negative organisms after $\mathbf{4 8}$ hours incubation, identified as Moraxella non liquefaciens sensitive to penicillin, ampicillin, tetracycline, streptomycin, and cephaloridine.

Bacteriological findings. A nonmotile Gramnegative coccobacillus was isolated after 48 hours' incubation at $37^{\circ}$ from each of two blood cultures containing cooked meat medium (oxoid) plus $0.05 \%$ liquoid. The properties of the organism were as follows. On horse blood agar, nonhaemolytic colonies aerobically, but no growth anaerobically. On MacConkey agar, no 